\title{
Exogenous Application of Melatonin Improves Drought Tolerance in Coffee by Regulating Photosynthetic Efficiency and Oxidative Damage
}

\author{
Sylvia Cherono \\ CAS Key Laboratory of Plant Germplasm Enhancement and Specialty Agriculture, Wuhan Botanical \\ Garden, The Innovative Academy of Seed Design, Chinese Academy of Sciences, Wuhan, Hubei \\ 430074, China; Centre of Economic Botany, Core Botanical Gardens, Chinese Academy of Sciences, \\ Wuhan, Hubei 430074, China; and University of Chinese Academy of Sciences, 19 A Yuquanlu, Beijing \\ 100049, China
}

\begin{abstract}
Charmaine Ntini, Misganaw Wassie, Mohammad Dulal Mollah, and Mohammad A. Belal CAS Key Laboratory of Plant Germplasm Enhancement and Specialty Agriculture, Wuhan Botanical Garden, The Innovative Academy of Seed Design, Chinese Academy of Sciences, Wuhan, Hubei 430074, China; and University of Chinese Academy of Sciences, 19A Yuquanlu, Beijing 100049, China
\end{abstract}

Collins Ogutu and Yuepeng Han

CAS Key Laboratory of Plant Germplasm Enhancement and Specialty Agriculture, Wuhan Botanical Garden, The Innovative Academy of Seed Design, Chinese Academy of Sciences, Wuhan, Hubei 430074, China; Centre of Economic Botany, Core Botanical Gardens, Chinese Academy of Sciences, Wuhan, Hubei 430074, China; and Sino-African Joint Research Centre, Chinese Academy of Sciences, Wuhan, Hubei 430074, China

AdDitional INDEX words. antioxidant enzymes, chlorophyll fluorescence, Coffea arabica, electrolyte leakage, malonaldehyde

\begin{abstract}
The protective role of melatonin in plants under abiotic stress has been reported, but little information is available on its mitigation effect on coffee (Coffea arabica) plants. The objective of this study was to determine the effect of exogenous application of $100 \mu \mathrm{M}$ melatonin in coffee leaves under 3 months of drought stress treatment. Melatonin was found to alleviate the drought-induced damage in coffee through reducing the rate of chlorophyll degradation, electrolyte leakage, malonaldehyde content, and activating various antioxidant enzymes, such as catalase, guaiacol peroxidase, and superoxide dismutase. Melatonin application suppressed the expression of chlorophyll degradation gene $P A O$ encoding pheophorbide $a$ oxygenase, and upregulated the expression of photosynthetic gene $R B C S 2$ encoding ribulose-1,5-bisphosphate oxygenase (Rubisco) protein, and a drought-related gene $A R E B$ encoding abscisic acid-responsive element binding protein. The photosynthetic efficiency of photosystem II under dark adaptation was also improved upon melatonin application in drought-stressed plants. Our results showed that both foliar spray and direct soil application of melatonin could improve drought tolerance by regulating photosynthetic efficiency and oxidative damage in $C$. arabica seedlings. This study provides insights in application of melatonin as a protective agent against drought stress in improvement of crop yields.
\end{abstract}

Drought is an environmental factor that causes stress in plants and restricts plant growth and development which has a great impact on crop production. It has been documented that drought stress reduces plant growth and productivity by impairing physiological and biochemical processes, such as photosynthesis, respiration, translocation, and growth pro-

Received for publication 18 June 2020. Accepted for publication 6 Oct. 2020. Published online 5 November 2020.

This project was supported by funds received from the Overseas Construction Plan for Science and Education Base, China-Africa Center for Research and Education, Chinese Academy of Sciences (Grant SAJC201327).

S.C. and C.O. conducted the experiments and prepared the manuscript. C.N., M.W., and M.D.M. helped with the experiments and manuscript revision. M.A.B. helped with data analysis. Y.H. was overall project leader and revised the manuscript.

C.O. and Y.H. are the corresponding authors. E-mail: collins@wbgcas.cn or yphan@wbgcas.cn.

This is an open access article distributed under the CC BY-NC-ND license (https://creativecommons.org/licenses/by-nc-nd/4.0/). moters. Plants control water loss during drought stress by adjusting stomatal opening to reduce transpiration flux and to limit $\mathrm{CO}_{2}$ absorption, resulting in reduction of net photosynthesis (DaMatta and Ramalho, 2006; Farooq et al., 2009; Jaleel et al., 2009; Liang et al., 2020). Drought stress can rapidly increase generation of toxic reactive oxygen species (ROS), such as superoxide anion $\left(\mathrm{O}_{2}^{-}\right)$, hydroxyl radical $(\bullet \mathrm{OH})$, and hydrogen peroxide $\left(\mathrm{H}_{2} \mathrm{O}_{2}\right)$, which can lead to severe toxicity by initiating an imbalance between the production of ROS and antioxidant defense. This damages cellular membranes and components, resulting to oxidative stress and eventual cell death (Farooq et al., 2009; Foyer and Fletcher, 2001; Talaat et al., 2015). In addition, over accumulation of ROS can impair cells' normal functions and cause lipid peroxidation, protein denaturation, photoinhibition, stomatal closure, and alteration of enzymes' activities (Farooq et al., 2009; Li et al., 2011). Plants have developed different enzymatic and nonenzymatic scavenging mechanisms to regulate ROS under environmental 
stresses. For example, under drought stress, elevated contents of malondialdehyde (MDA) and electrolyte leakage (EL) are often used as indicators of oxidative damage to plant cell membranes (Li et al., 2011; Lima et al., 2002). To increase drought tolerance, plants enhance the activities of scavenging enzymes such as superoxide dismutase (SOD), catalase (CAT), and guaiacol peroxidase (POD) (Mittler, 2006). Similarly, plants adopt nonenzymatic mechanisms including decreased canopy size and closed stomata to minimize water loss (Wang et al., 2019).

Coffee is a widely consumed beverage and the second mosttraded global commodity. It belongs to the genus Coffea, subgenus Coffea in the Rubiaceae family with $\approx 124$ species. The main species cultivated are the tetraploid $(2 n=4 x=44), C$. arabica, which accounts for about $65 \%$ of global production; and the two diploid $(2 n=2 x=22)$ species, $C$. canephora and $C$. liberica, which account for about $30 \%$ of global production (Bita and Preda, 2005; DaMatta, 2004; Ribas et al., 2006). Drought is a major environmental constraint that has led to $\approx 80 \%$ decrease in global coffee production (DaMatta, 2004; DaMatta and Ramalho, 2006; Pinheiro et al., 2005). Therefore, developing strategies to enhance drought resistance and improve productivity in coffee is warranted.

Exogenous application of phytohormones and plant growth regulators, such as melatonin, salicylic acid, jasmonic acid, ethylene, and abscisic acid (ABA), has been shown to enhance drought-stress tolerance in plants (Arnao and Hernandez-Ruiz, 2018; Li et al., 2013). Melatonin (N-acetyl-5-methoxytryptamine) is a low molecular weight tryptophan-derived hormone with an indole ring structure. It is produced by the vertebrate pineal gland and was initially identified as an animal hormone that regulates the circadian rhythms and sleep (Calvo et al., 2013; Korkmaz et al., 2009; Reiter, 1997; Tan et al., 2000, 2012). In plants, melatonin was first detected using highperformance liquid chromatography (HPLC) and radioimmunoassay (Hattori et al., 1995), and many studies have been carried out to elucidate its functions in regulating growth. Melatonin has been associated with plant protection against biotic and abiotic stress as an antioxidant (Afreen et al., 2006). For example, melatonin lessens oxidative damage during drought stress by directly scavenging ROS, and by enhancing antioxidant enzymes activities, thus maintaining plant membrane integrity (Allegra et al., 2003; Tan et al., 2000).

Recently, its role as a signaling hormone was reported, suggesting that plants tend to accumulate higher levels of melatonin under drought stress (Arnao and Hernandez-Ruiz, 2014). In addition, studies have demonstrated that melatonin can alleviate effects of extreme environmental stress such as cold (Kang et al., 2010; Lei et al., 2004), salinity (Jiang et al., 2016; Li et al., 2012), heavy metals (Nabi et al., 2019; Posmyk et al., 2008; Tan et al., 2007), leaf senescence (Ma et al., 2018; Wang et al., 2013), and ultraviolent radiation (ultraviolet) (Afreen et al., 2006) in various plants. Melatonin can maintain plant membrane integrity by directly scavenging ROS. Despite numerous studies on the antioxidative properties of melatonin that have been conducted in plants such as apple (Malus $\times$ domestica), soybean (Glycine max), cucumber (Cucumis sativus), and maize (Zea mays) (Huang et al., 2019; Liang et al., 2018; Wei et al., 2015; Zhang et al., 2013), little is known about its role in improving the tolerance of coffee plants to biotic and abiotic stresses. We explored the effects of melatonin on the dynamics of antioxidant enzymatic activity, lipid peroxidation, photosynthetic efficiency, and EL in C. arabica seedlings under drought stress. Exogenous melatonin application not only showed an effect on the activities of various antioxidant enzymes such as CAT, POD, and SOD, but could also reduce MDA and EL, which are important indicators of cellular membrane integrity. Melatonin could also alleviate chlorophyll degradation in plants exposed to drought stress. Our results provide an insight into the mechanism underlying the regulatory role of melatonin in improving tolerance of coffee to drought stress.

\section{Materials and Methods}

Plant materials. All coffee seedlings used in this study were maintained and cultivated in the greenhouse at the Institute of Wuhan Botanical Garden, Chinese Academy of Sciences, China. One-year-old $C$. arabica seedlings were cultivated in a growth chamber with a temperature regime of 25/ $20{ }^{\circ} \mathrm{C}$ (day/night), photosynthetically active radiation $(P A R)$ levels of $300 \mu \mathrm{mol} \cdot \mathrm{m}^{-2} \cdot \mathrm{s}^{-1}, 70 \%$ relative humidity, and a photoperiod of 14/10 h (light/dark) (Carr, 2001; Fahl et al., 1994; Fanjul et al., 2008). Plants were grown in plastic pots (10 $\times 17 \mathrm{~cm}$ ) filled with forest top soil/sand (5 soil: 1 sand, v/v) with $5 \mathrm{~g} /$ pot $10 \mathrm{~N}-6.1 \mathrm{P}-6.8 \mathrm{~K}$ fertilizer added $\left(52 \mathrm{~kg} \cdot \mathrm{ha}^{-1} \mathrm{~N}\right)$. The pots were covered with impervious clear paper to prevent excessive water loss. Before the onset of the experiment, all plants were well-watered daily and fertilized with half-strength Hoagland's solution ( $\mathrm{pH}$ 6.0) twice per week (Hoagland and Arnon, 1950). After 3 months of growth, plants were selected for treatments. Three treatment groups were arranged in a randomized complete block design with five replicates each: well-watered (WW), drought-stressed (D), drought-stressed along with melatonin treatment (DM). For the well-watered treatment, plants were irrigated with water for the rest of the treatment. For the melatonin treatment, $C$. arabica plants were treated with melatonin (Sigma-Aldrich, St. Louis, MO) three times per week using both foliar spraying and application into the soil at the same concentration of $100 \mu \mathrm{M}$ as previously reported (Kabiri et al., 2018; Zhang et al., 2013). About $20 \mathrm{~mL}$ of melatonin was sprayed on each plant and $30 \mathrm{~mL}$ applied directly to the soil. Three pots without plants for each drought treatment group were used for monitoring evaporative water loss throughout the experimental period. Water loss was evaluated by weighing the pots weekly to maintain the soil water content at $40 \%$ field capacity and calculating changes in weight that occurred as a result of evaporative water loss between watering regimes. The amount of water lost was then added back to the DM and D plants in alternate days to maintain similar moisture content. Leaf samples were collected after every month from each treatment, immediately frozen in liquid nitrogen, and then stored at $-80{ }^{\circ} \mathrm{C}$ for subsequent analysis of physiological traits and gene expression.

MEASUREMENT OF CHLOROPHYLl CONTENT AND FLUORESCENCE. Chlorophyll (Chl) content was determined according to a previously reported method (Li et al., 2018; Liang et al., 2017; Lichtenthaler, 1987) with slight modifications. Briefly, $0.1 \mathrm{~g}$ fresh C. arabica leaf samples were extracted with $95 \%$ alcohol. The tubes were wrapped with aluminium foil and incubated for $48 \mathrm{~h}$ in darkness at room temperature. The absorbance was assayed with a spectrophotometer (ultraviolet-1100; Macy Instruments, Shanghai, China) at 665 and $649 \mathrm{~nm}$ wavelength. Chlorophyll concentration was calculated using the following formulae: Chl a [milligrams 
per gram fresh weight $(\mathrm{FW})]=\left(13.95 \times \mathrm{A}_{665}-6.88 \times \mathrm{A}_{649}\right) \times$ $0.005 \div \mathrm{W}$; Chl b (milligrams per gram $\mathrm{FW})=\left(24.96 \times \mathrm{A}_{649}-\right.$ $\left.7.32 \times \mathrm{A}_{665}\right) \times 0.005 \div \mathrm{W}$; total $\mathrm{Chl}$ (milligrams per gram $\mathrm{FW})=\mathrm{Chl} \mathrm{a}+\mathrm{Chl} \mathrm{b}=\left(18.08 \times \mathrm{A}_{649}+6.63 \times \mathrm{A}_{665}\right) \times 0.005 \div \mathrm{W}$, where $\mathrm{A}$ and $\mathrm{W}$ are the absorbance of chlorophyll extract and the leaf FW (grams), respectively.

The chlorophyll fluorescence parameters of coffee leaves were determined with a portable photosynthesis system (PAM2500; Heinz Walz, Eichenring, Germany). Fully expanded third leaves were used for chlorophyll fluorescence analysis. Briefly, leaves were pre-adapted in the dark for $30 \mathrm{~min}$ before measurement. All measurements were taken using a saturating light intensity of $2000 \mu \mathrm{mol} \cdot \mathrm{m}^{-2} \cdot \mathrm{s}^{-1}$. For each treatment group, five measurements were taken for each month with a high time resolution of $10 \mu \mathrm{s}$ and $300 \mathrm{~ms}$. Typical polyphasic OJIP curve, where $\mathrm{O}$ is the initial fluorescence, $\mathrm{J}$ and I sites are intermediate transients, and $\mathrm{P}$ is the peak fluorescence, was analyzed using the JIP-test (Yusuf et al., 2010). Basic fluorescence parameters, specific energy fluxes, quantum yield efficiency, and performance index were extracted and analyzed (Table 1).

Measurement of MDA Content and EL. The amount of MDA was determined according to a previously reported protocol (Fan et al., 2015; Heath and Packer, 1968; Hu et al., 2018). About $1 \mathrm{~mL}$ crude enzyme extract was added to $2 \mathrm{~mL}$ reaction solution containing 20\% (v/v) trichloroacetic acid (TCA) and $0.5 \%(\mathrm{v} / \mathrm{v})$ thiobarbituric acid (TBA). The mixture was heated for $30 \mathrm{~min}$ at $95^{\circ} \mathrm{C}$, cooled on ice, and centrifuged at $14,000 \mathrm{~g}_{\mathrm{n}}$ for $10 \mathrm{~min}$ at $20{ }^{\circ} \mathrm{C}$. The supernatant was collected for absorbance measurement with an ultraviolet-visible spectrophotometer (ultraviolet-1100) at 532 and $600 \mathrm{~nm}$. The absorbance at $600 \mathrm{~nm}$ was deducted for correction of nonspecific turbidity. MDA content was calculated as MDA (nanomoles per gram $\mathrm{FW})=\left[\left(\mathrm{A}_{532}-\mathrm{A}_{600}\right) \times \mathrm{V} \times 1000 / \varepsilon\right]$ $\times \mathrm{W}$, where $\varepsilon$ is the specific extinction coefficient of $155 \mathrm{~mm} \cdot \mathrm{cm}^{-1}$, while $\mathrm{V}$ and $\mathrm{W}$ represent the volume of extraction solution (milliliters) and the FW of the leaf sample (grams), respectively. EL was assayed as previously described in Shi et al. (2015). About $0.5 \mathrm{~g}$ of fresh samples was transferred into a $50-\mathrm{mL}$ tube filled with deionized water. The tubes were incubated at room temperature for $12 \mathrm{~h}$ on a conical shaker, and primary conductivity (EL1) was determined using a conductance meter (3137; Jenco Instruments, San Diego, CA). To release all electrolytes, the leaf samples were autoclaved at $121{ }^{\circ} \mathrm{C}$ for $30 \mathrm{~min}$. After cooling them at room temperature, we determined the secondary conductivity (EL2) using the same method as for EL1. The relative electrolyte leakage was calculated as relative EL $(\%)=(E L 1 / E L 2) \times 100$.

Crude enzyme extraction. For crude enzyme extraction, $\approx 0.5 \mathrm{~g}$ of fresh coffee leaf samples frozen in liquid nitrogen were ground into powder using a prechilled mortar and pestle $\left(4^{\circ} \mathrm{C}\right)$ in liquid nitrogen. Then, $6 \mathrm{~mL}$ of a $150-\mathrm{mm}$ sodium phosphate buffer (PBS), $\mathrm{pH} 7.0$, was added to the powder. The homogenate was then centrifuged at $4{ }^{\circ} \mathrm{C}$ for $20 \mathrm{~min}$ at $15,000 \mathrm{~g}_{\mathrm{n}}$, and the supernatant was collected and subjected to antioxidant enzyme activity assay and MDA content determination according to a previously reported protocol (Willekens et al., 1997).

Antioxidant Enzyme aCtivity assay. The enzyme activities of POD (EC 1.11.1.7) and SOD (EC 1.15.1.1) were assayed using the reagent kit (Jiancheng Bioengineering Institute, Nanjing, China) according to the manufacturer's instruction. CAT (EC 1.11.1.6) activity was measured using the previously reported method (Aebi, 1984) with slight modifications. The reaction mixture contained $0.1 \mathrm{~mL}$ crude enzyme extract, 1.90 $\mathrm{mL}$ of $50-\mathrm{mmol} \cdot \mathrm{L}^{-1} \mathrm{PBS}(\mathrm{pH} 7.0)$. CAT activity was measured

Table 1. Changes in modulated chlorophyll fluorescence parameters during drought stress in leaves of Coffea arabica seedlings.

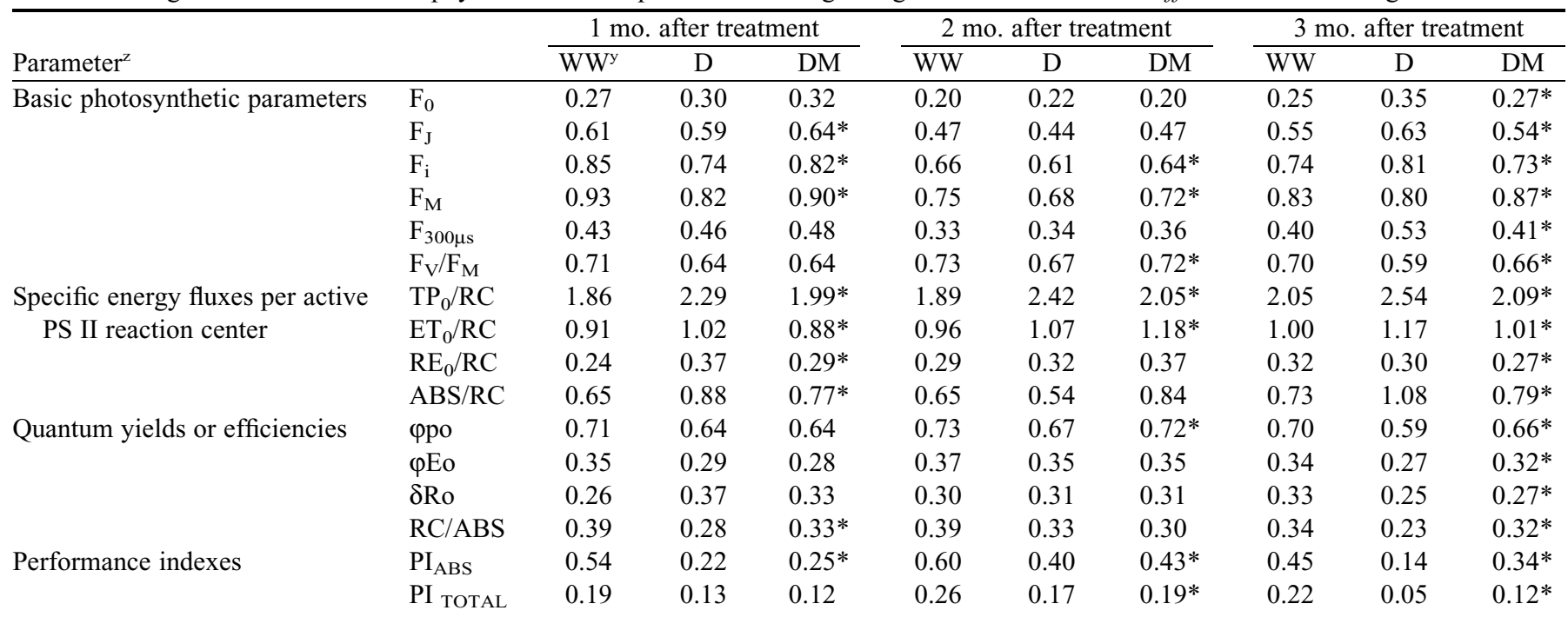

${ }^{\mathrm{z}}$ Basic photosynthetic parameters: $\mathrm{F}_{0}=$ minimal fluorescence at time $t$ after onset of actinic illumination; $\mathrm{F}_{\mathrm{J}}=$ fluorescence intensity at the $\mathrm{J}$-step $(2 \mathrm{~ms})$ of OJIP; $\mathrm{F}_{\mathrm{I}}=$ fluorescence intensity at the I-step $(30 \mathrm{~ms})$ of OJIP; $\mathrm{F}_{\mathrm{M}}=$ maximal fluorescence; $\mathrm{F}_{300 \mu \mathrm{s}}=$ fluorescence intensity at $300 \mu \mathrm{s}$; $\mathrm{F}_{\mathrm{V}} / \mathrm{F}_{\mathrm{M}}=$ maximum quantum efficiency at PSII photochemistry. Specific energy fluxes per active PS II reaction center $(\mathrm{RC}): \mathrm{TP} / \mathrm{RC}=\operatorname{trapped}$ excitation flux per $\mathrm{RC} ; \mathrm{ET}_{0} / \mathrm{RC}=$ electron transport flux per $\mathrm{RC} ; \mathrm{RE}_{0} / \mathrm{RC}=$ electron flux reducing end electron acceptors at the PS I acceptor side per RC; $\mathrm{ABS} / \mathrm{RC}=$ absorption photon flux per RC. Quantum yields or efficiencies: $\varphi p o=$ maximum quantum yield for primary photochemistry; $\varphi \mathrm{Eo}=$ quantum yield of the electron transport flux; $\delta \mathrm{Ro}=$ efficiency/probability with which an electron from the intersystem electron is transported to the PSI acceptor $(\mathrm{RE}) ; \mathrm{RC} / \mathrm{ABS}=\mathrm{QA}$-reducing RCs per PSII antenna. Performance Index $\left(\mathrm{PI}_{\mathrm{ABS}}\right.$ and $\left.\mathrm{PI} T \mathrm{TOTAL}\right)=\mathrm{Performance}$ Index (potential) for energy conservation from exciton to the reduction of PSI end acceptors.

${ }^{\mathrm{y}} \mathrm{WW}=$ well-watered; $\mathrm{D}=$ drought-stressed; $\mathrm{DM}=$ drought-stressed along with melatonin treatment groups. The data in the table are mean $(\mathrm{n}=$ 5), and asterisks indicate statistical significance difference between DM and D at a threshold of $P<0.05$ based on Tukey's test. 
by monitoring the decrease in absorbance once every minute within the first 3 minutes caused by the decomposition of $\mathrm{H}_{2} \mathrm{O}_{2}$.

RNA EXTRACTION AND REAL-TIME PCR (QRT-PCR) ANALYSIS. Extraction of total RNA for each sample was performed using an RNAprep Plant Kit (Tiangen, Beijing, China) according to the manufacturer's instructions. Synthesis of cDNA was carried out using a PrimeScript RT reagent Kit with gDNA Eraser (Takara, Dalian, China) following the manufacturer's instructions. We performed qRT-PCR in a $20-\mu \mathrm{L}$ reaction volume containing $10 \mu \mathrm{L}$ TB Green Premix Ex Taq II (Takara), $6 \mu \mathrm{L}$ ddH $_{2} \mathrm{O}, 0.8 \mu \mathrm{L}$ forward primer $(10 \mu \mathrm{M}), 0.8 \mu \mathrm{L}$ reverse primer $(10 \mu \mathrm{M}), 0.4 \mu \mathrm{L}$ ROX reference dye $(50 \mathrm{X})$, and $2 \mu \mathrm{L}$ template cDNA. PCR amplification was performed on an Applied Biosystems Step One Plus Real-Time PCR System (Thermo Fisher Scientific, Waltham, MA) using the following program: initial denaturation $95{ }^{\circ} \mathrm{C}$ for $30 \mathrm{~s}, 40$ cycles at $95^{\circ} \mathrm{C}$ for $5 \mathrm{~s}$, and $60^{\circ} \mathrm{C}$ for $30 \mathrm{~s}$. Gene transcript abundance was calculated using the $2^{-\Delta \Delta C}$ comparative threshold cycle (CT) method as previously described by Livak and Schmittgen (2001). Each treatment was conducted with three biological replicates. The primer sequences used in this study are listed in Supplemental Table 1.
Statistical ANAlysis. Statistical analysis was performed using one-way analysis of variance combined with Tukey's test using SPSS software (version 22.0; IBM Corp., Armonk, NY) at a significance level of $P<0.05$. Data were presented as mean \pm SE $(n=5)$. All figures were created by Origin 9.0 (Origin Laboratory, Hampton, MA).

\section{Results}

EFFECT OF MELATONIN ON CHLOROPHYLL CONTENT AND FLUORESCENCE PARAMETERS IN LEAVES OF COFFEE PLANTS UNDER DROUGHT STRESS. The contents of $\mathrm{Chl} \mathrm{a}, \mathrm{Chl} \mathrm{b}$, and total Chl were all significantly lower in plants with either droughtstressed (D) or drought-stressed along with melatonin treatment (DM) than in plants well-watered (WW), after treatment for 1 month (Fig. 1A). Significant difference in the content of $\mathrm{Chl}$ a, $\mathrm{Chl} \mathrm{b}$, and total Chl was observed between D and DM treatments at the second and third month, although there was no significant difference for the first month of treatment. The

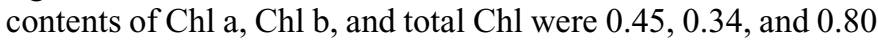
$\mathrm{mg} \cdot \mathrm{g}^{-1} \mathrm{FW}$, respectively, in $\mathrm{D}$ plants at the third month of
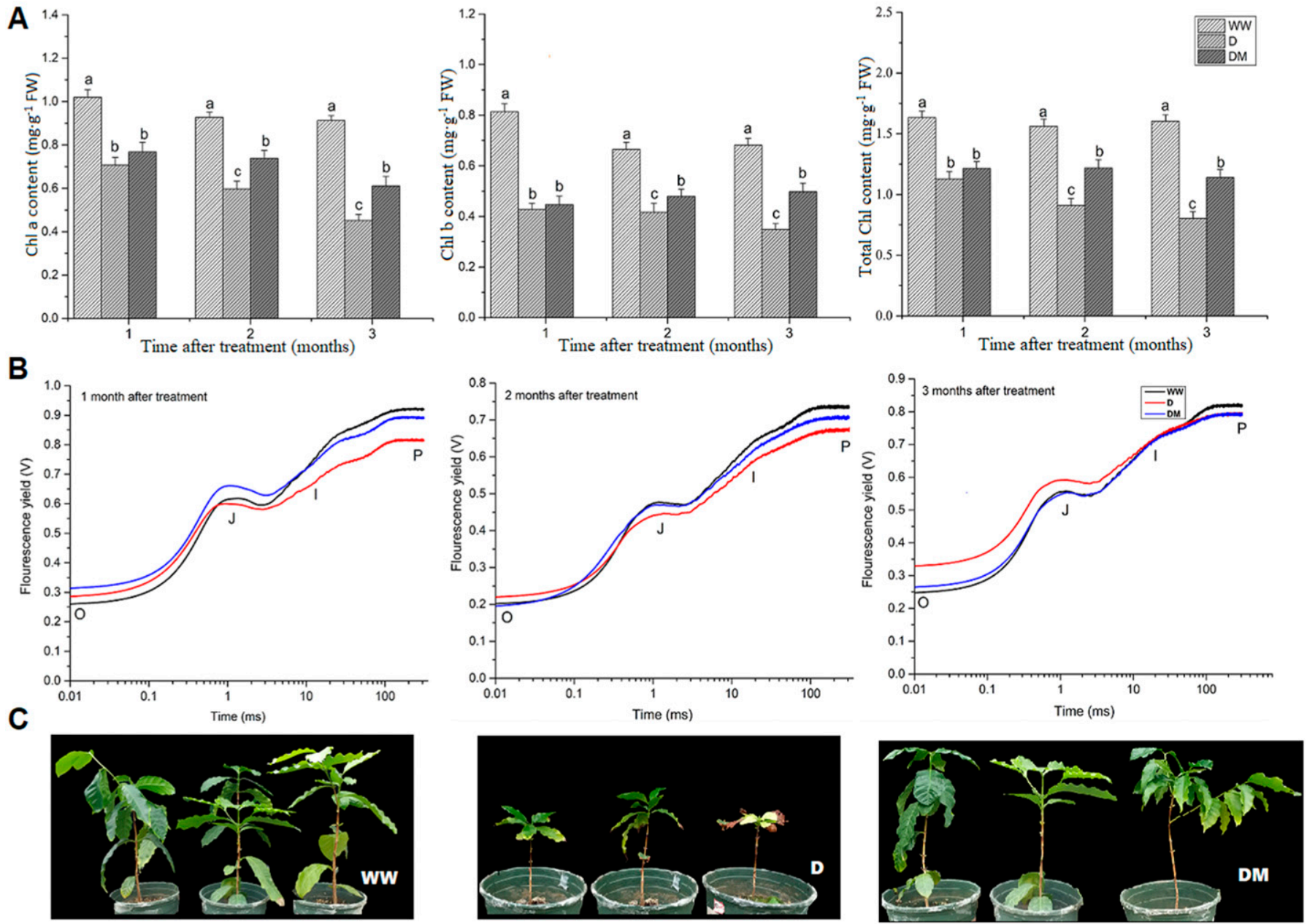

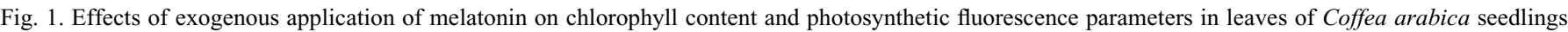
under 3 months of drought stress treatment. (A) The content of chlorophyll, Chl a, Chl b, and total Chl in leaves of seedlings under different treatments. Data represent means \pm SE $(n=5)$. Columns marked with different letters indicate significant differences between the treatments for each month based on Tukey's test $(P<0.05)$. (B) Photosynthetic efficiency of chlorophyll fluorescence intensity (V) relative to time for leaves of seedlings under different treatments. $(\mathbf{C})$ Coffee seedlings after treatment for 3 months with different stresses. WW, D, and DM represent well-watered control, drought-stressed, drought-stressed along with melatonin treatment, respectively. 
treatment, but with corresponding values of $0.61,0.49$, and 1.13 $\mathrm{mg} \cdot \mathrm{g}^{-1} \mathrm{FW}$ in DM plants. Water deficit adversely affected chlorophyll fluorescence transient curve in D plants, causing the curve to significantly decline (Fig. 1B). In contrast, melatonin ameliorated the drought effect, resulting in an increase in the OJIP curve. Greater variation in the course of transient curve was observed at the O-J and I-P phase, with higher transient course in D and DM plants respective to WW plants. After 3 months of treatment, leaf senescence occurred in D plants, but this was not obvious in WW and DM plants (Fig. 1C).

Basic photosynthetic parameters were measured, and the results are shown in Table 1 . Highest minimal fluorescence $\left(\mathrm{F}_{0}\right)$ yield values were detected in D plants, whereas the values were significantly decreased in DM plants. Prolonged stress resulted in a consistent decrease in maximal fluorescence intensity $\left(\mathrm{F}_{\mathrm{M}}\right)$ and maximum quantum efficiency at the photosystem II (PSII) photochemistry $\left(\mathrm{F}_{\mathrm{V}} / \mathrm{F}_{\mathrm{M}}\right)$, in D plants relative to WW plants. However, the $F_{M}$ and $F_{V} / F_{M}$ increased significantly in the DM plants with melatonin treatment compared with D plants. Additionally, a significant increase in specific energy fluxes was detected in D plants relative to WW plants, including trapped excitation flux $\left(\mathrm{TP}_{0}\right)$, per PSII reaction center $(\mathrm{RC})$, electron transport flux $\left(\mathrm{ET}_{0}\right)$, per $\mathrm{RC}$, electron flux reducing end electron acceptors at the PSII acceptor side $\left(\mathrm{RE}_{0}\right)$, per $\mathrm{RC}$, and absorption photon flux (ABS), per RC. A significant decrease in the fluxes was observed in DM plants respective to D plants. Similarly, melatonin treatment significantly increased quantum yield efficiency components, maximum quantum yield ( $\varphi p o)$, quantum yield of the electron transport flux $(\varphi \mathrm{Eo})$ and primary quinone electron acceptor of PS II, reducing RCs per PSII antenna (RC/ABS), and performance indexes $\left(\mathrm{PI}_{\mathrm{TOTAL}}\right.$ and $\mathrm{PI}_{\mathrm{ABS}}$ ), in DM plants respective to D plants. Altogether, these results suggested that melatonin application improved PSII function under drought stress.

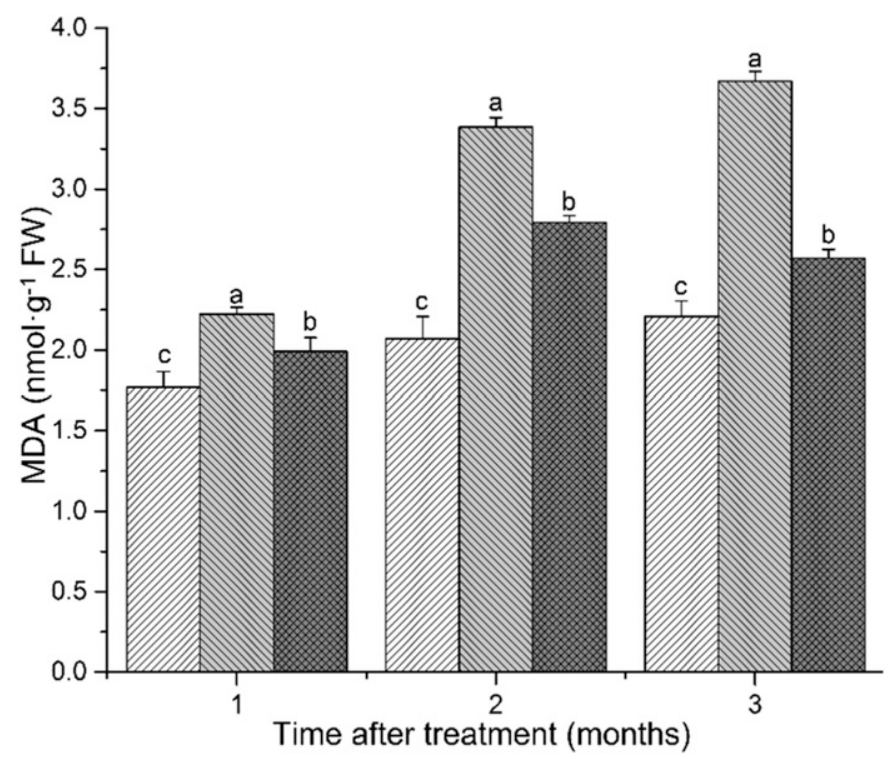

EFFEct of MELATONin ON MDA CONTENT AND EL IN PLANTS UNDER DROUGHT STRESS. Seedlings of $C$. arabica under drought stress exhibited increased levels of MDA and EL, which suggested lipid membrane peroxidation and cell membrane damage (Fig. 2A). Under drought stress, MDA content increased rapidly in D plants, with $2.22,3.38$, and $3.67 \mathrm{nmol} \cdot \mathrm{g}^{-1}$ FW, at the first, second, and third month, respectively. In contrast, MDA content showed a relatively slow increase in DM plants, with $1.99,2.79$, and $2.56 \mathrm{nmol} \cdot \mathrm{g}^{-1} \mathrm{FW}$ in the first, second, and third month, respectively. Similarly, EL values were $8.4 \%, 18.9 \%$, and $20.5 \%$ in D plants at the first, second, and third month, respectively, but with decreased values of $6.9 \%, 16.8 \%$, and $15.7 \%$ in DM plants (Fig. 2B). These results indicated that exogenous application of melatonin inhibited the increase of both MDA content and EL of coffee plants under drought stress, leading to a reduction in lipid membrane peroxidation and alleviation of damage of cell membrane integrity and stability.

Melatonin ENhanCED EnZYMatic antioxidant ACTIVITY IN COFFEE PLANTS. Activities of $0.8,0.9$, and $1.0 \mathrm{U} / \mathrm{mg} \mathrm{FW}$ for SOD; $1.9,2.9$, and $3.3 \mathrm{U} / \mathrm{mg}$ protein for POD; and 1.9, 2.7, and $3.4 \mathrm{U} / \mathrm{g} \mathrm{FW}$ for CAT were detected in D plants at the first, second, and third month, respectively (Fig. 3). In contrast, enhanced enzyme activities of 1.0, 1.2, and 1.2 U/mg FW for SOD; $2.8,3.6$, and $3.8 \mathrm{U} / \mathrm{mg}$ protein for POD; and 2.8, 3.6, and $3.8 \mathrm{U} / \mathrm{g} \mathrm{FW}$ for CAT were observed in DM plants at the first, second, and third month, respectively. This suggested that oxidative stress induced antioxidant enzyme activities of SOD, POD, and CAT in coffee plants under drought stress, and this induction could be enhanced by exogenous application of melatonin.

EFFECT OF MELATONin ON RELATIVE EXPRESSion of $\boldsymbol{P} \boldsymbol{A} \boldsymbol{O}$, $\boldsymbol{R} B S C 2$, AND $A R E B$ GENES. Relative expression of a chlorophyll degradation gene $P A O$ encoding pheophorbide- $a$-oxygenase, a photosynthetic gene $R B C S 2$ encoding photosynthetic ribulose-1,5bisphosphate oxygenase (Rubisco) protein, and a drought-related

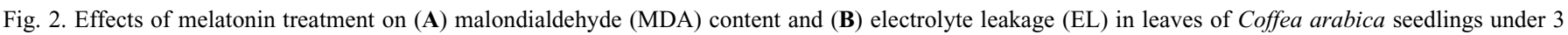
months of drought stress treatment. Data represent means $\pm \mathrm{SE}(\mathrm{n}=5)$. Columns marked with different letters indicate significant differences between the treatments for each month based on Tukey's test $(P<0.05)$. WW, D, and DM represent well-watered control, drought-stressed, and drought-stressed along with melatonin treatment, respectively. 

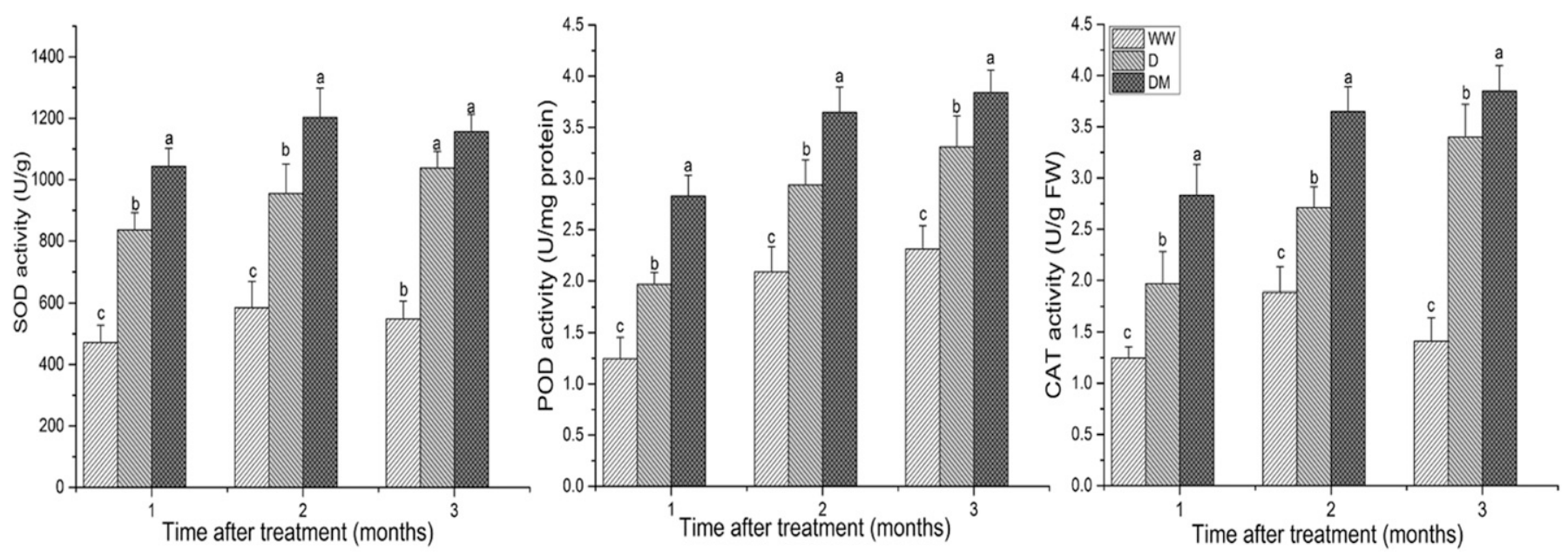

Fig. 3. Melatonin application enhances enzymatic antioxidant activity in leaves of Coffea arabica seedlings under 3 months of drought stress treatment. Catalase (CAT), guaiacol peroxidase (POD), and superoxide dismutase (SOD). Data represent means \pm SE $(n=5)$. Columns marked with different letters indicate significant differences between the treatments for each month based on Tukey's test $(P<0.05)$. WW, D, and DM represent well-watered control, drought-stressed, and drought-stressed along with melatonin treatment, respectively.
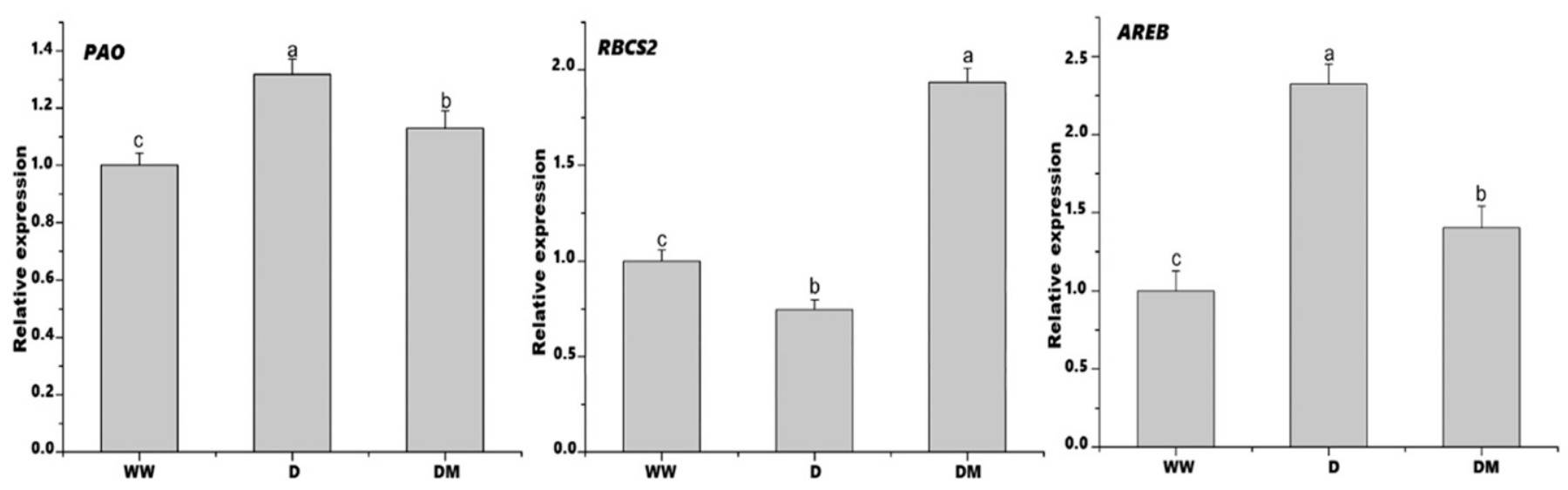

Fig. 4. Effects of melatonin application on relative expression of pheophorbide $a$ oxygenase $(P A O)$, ribulose-1,5-bisphosphate oxygenase (Rubisco) protein (RBSC2), abscisic acid-responsive element binding protein $(A R E B)$ in leaves of Coffea arabica seedlings under 3 months of drought stress treatment. Data represent means $\pm \mathrm{SE}(\mathrm{n}=5)$. Columns marked with different letters indicate significant differences between the treatments for each month based on Tukey's test $(P<0.05)$. WW, D, and DM represent well-watered control, drought-stressed, and drought-stressed along with melatonin treatment, respectively.

gene $A R E B$ encoding abscisic acid-responsive binding protein were investigated, and the results are shown in Fig. 4. The expression of $P A O$ and $A R E B$ was significantly increased by 1.3- and 2.3-fold, respectively, in D plants respective to WW plants. However, their expression was significantly downregulated in DM plants with melatonin application respective to D plants. In addition, the expression of $R B S C 2$ was downregulated in D plants relative to WW plants, but it showed a significant increase by 1.9 -fold in DM plants. In summary, down-regulation of $P A O, A R E B$ genes and up-regulation of $R B S C 2$ in DM plants respectively to D plants suggested that melatonin reduced photosynthesis degradation and enhanced ABA signaling, leading to an improved drought tolerance.

\section{Discussion}

Melatonin is a plant growth regulator and a free radical scavenger (Huang et al., 2019; Liang et al., 2018; Wei et al., 2015; Zhang et al., 2013) that enhances antioxidant enzymes activities during stress (Afreen et al., 2006; Allegra et al., 2003; Campos et al., 2003; Ding et al., 2018; Tan et al., 2000). In this study, application of melatonin enhanced drought tolerance and delayed leaf senescence in coffee seedlings. Previously, melatonin has been associated with delayed chlorophyll degradation by increasing the overall chlorophyll content under abiotic stress (Chen et al., 2009; Huang et al., 2019; Wang et al., 2013). Similarly, our results indicated that exogenous melatonin application increased the levels of $\mathrm{Chl} \mathrm{a}, \mathrm{Chl} \mathrm{b}$, and total Chl under drought stress, thus increasing capacity for light harvesting in coffee seedlings.

A significant increase in the chlorophyll fluorescence OJIP transient curve suggests that melatonin ameliorates the adverse effects of drought, especially at the O-J and I-P phase, where the greatest impact of drought stress is - probably due to oxidation of electron transport chains, resulting from the reduction in the electron donor of PSII reaction centers (Calatayud et al., 2006; Yusuf et al., 2010). The analysis of chlorophyll fluorescence parameters response to melatonin treatment revealed higher $\mathrm{F}_{0}$ 
values in coffee plants under drought stress relative to droughtstressed plants with exogenous melatonin application. Under water deficit, increased $\mathrm{F}_{0}$ alters photosynthetic metabolism through delayed electron transfer in the PSII sites, causing chloroplast damage, thus reducing plant photosynthetic activity (Calatayud et al., 2006; Maxwell and Johnson, 2000; Murchie and Lawson, 2013). Decreased $F_{0}$ in coffee seedlings treated with melatonin demonstrates the hormone's role in establishing consistent electron flow at the donor and acceptor sites of PSII, which improves photosynthetic capacity (Murchie and Lawson, 2013). The $F_{0}$ values were also observed to decrease with increasing chlorophyll content in leaves. In addition, melatonin showed a positive effect on chlorophyll florescence in droughtstressed coffee plants as evidenced by a markedly high $\mathrm{F}_{\mathrm{V}} / \mathrm{F}_{\mathrm{M}}$ ratio, which indicates a reduction in energy loss and PSII maximum efficiency (Liu et al., 2016). Enhanced levels of specific energy flux parameters (such as $\mathrm{TP}_{0} / \mathrm{RC}, \mathrm{ET}_{0} / \mathrm{RC}, \mathrm{RE}_{0} /$ $\mathrm{RC}$, and $\mathrm{ABS} / \mathrm{RC}$ ) in drought-stressed coffee plants indicates inactivation of light absorption and trapping reaction centers due to abiotic stress causing a reduction of energy-trapping efficiency from PSII (Liu et al., 2016; Strasser et al., 2000). However, melatonin treatment significantly decreases specific energy flux parameters and promotes photosynthetic capacity and plant vitality, thus demonstrating its ability to induce light absorption in coffee plants under stress (Chen et al., 2013; Murchie and Lawson, 2013; Strasser et al., 2000). Quantum yield efficiency components $\varphi$ po, $\varphi$ Eo, and RC/ABS as well as $\mathrm{PI}_{\mathrm{ABS}}$ and $\mathrm{PI}_{\mathrm{TOTAL}}$ significantly increased in drought-stressed plants treated with melatonin than in drought-stressed plants, which indicates the positive role of melatonin in activating flow of electrons between PSII complexes, thus maintaining photosynthetic activity of coffee plants under drought stress (Chen et al., 2013; Liu et al., 2016). It is however worth noting that plant water status is a key physiological parameter in evaluating drought-stress studies in plants and should be evaluated in future studies.

Lipid peroxidation and EL are indicators of plant cell membrane damage, ion leakage, and impaired function (Farooq et al., 2009). A significant increase in MDA and EL was observed in drought-stressed coffee seedlings, suggesting oxidative damage, decreased membrane fluidity, and altered ion homeostasis due to rapid accumulation of ROS (Li et al., 2011). In contrast, melatonin application significantly decreased the levels of MDA and EL, thus alleviating ROS burst and decreasing oxidative injury of cell membranes. A consistent increase in both MDA and EL observed throughout the whole treatment demonstrates that the extent of cell membrane damage is affected by the duration of stress, which is consistent with previous reports in maize, soybean, and cucumber (Huang et al., 2019; Kabiri et al., 2018; Wei et al., 2015; Zhang et al., 2013). Oxidative stress due to over-accumulation of ROS can induce antioxidant enzyme activities in plants (Posmyk et al., 2008; Shi et al., 2015). In this study, oxidative stress dramatically activated SOD, POD, and CAT during drought stress, while their activities were enhanced upon melatonin application on coffee seedlings. This suggests that melatonin can act as an ROS scavenger through activation of antioxidant enzymes ROS detoxification to maintain equilibrium of the cellular ROS at a low level (Reiter et al., 2000; Shi et al., 2015; Xia et al., 2020). In addition, a high expression of chlorophyll degradation $P A O$ gene in drought-stressed plants was down-regulated by melatonin application. The drought response $A R E B$ gene (which activates stress related genes in plants tissues) was upregulated in drought-stressed coffee seedlings, but down-regulated upon melatonin application. Moreover, the expression of the photosynthetic RBCS2 gene was down-regulated in drought-stressed plants, which could be attributed to chloroplast damage (Bartholomew et al., 1991; Fujita et al., 2005; Kang et al., 2002; Lu et al., 2009; Mofatto et al., 2016; Orellana et al., 2010; Rizhsky et al., 2002), but up-regulated upon melatonin application. Altogether, these results provide strong evidence of the antagonistic role of melatonin during drought stress in reducing damage of chlorophyll and photosynthetic activity in coffee seedlings.

In conclusion, our study demonstrates the mitigating effects of exogenous application of melatonin on coffee seedlings under drought stress. Melatonin could improve photosynthetic efficiency, delay leaf senescence, and enhance antioxidant enzymes activities, thus eliminating ROS to improve drought tolerance in $C$. arabica plants. To our knowledge, our study provides for the first time an evidence of the protective role of exogenous application of melatonin in coffee seedlings, which can be crucial for plant survival and improved yields in dry environments.

\section{Literature Cited}

Aebi, H. 1984. Catalase in vitro. Methods Enzymol. 105:121-126, doi: 10.1016/S0076-6879(84)05016-3.

Afreen, F., S.M. Zobayed, and T. Kozai. 2006. Melatonin in Glycyrrhiza uralensis: Response of plant roots to spectral quality of light and UV-B radiation. J. Pineal Res. 41:108-115, doi: 10.1111/j.1600079X.2006.00337.x.

Allegra, M., R.J. Reiter, D.X. Tan, C. Gentile, L. Tesoriere, and M.A. Livrea. 2003. The chemistry of melatonin's interaction with reactive species. J. Pineal Res. 34:1-10, doi: 10.1034/j.1600079x.2003.02112.x.

Arnao, M.B. and J. Hernandez-Ruiz. 2014. Melatonin: Plant growth regulator and/or biostimulator during stress? Trends Plant Sci. 19:789-797, doi: 10.1016/j.tplants.2014.07.006.

Arnao, M.B. and J. Hernandez-Ruiz. 2018. Melatonin and its relationship to plant hormones. Ann. Bot. 121:195-207, doi: 10.1093/aob/ mex114.

Bartholomew, D.M., G.E. Bartley, and P.A. Scolnik. 1991. Abscisic acid control of $r b c S$ and $c a b$ transcription in tomato leaves. J. Plant Physiol. 96:291-296, doi: 10.1104/pp.96.1.291.

Bita, M.G. and M. Preda. 2005. The effect of temperature and roasting degree on the total phenolic content of coffee brews. Sci. Study Res. VI:239-242.

Calatayud, A., D. Roca, and P.F. Martinez. 2006. Spatial-temporal variations in rose leaves under water stress conditions studied by chlorophyll fluorescence imaging. Plant Physiol. Biochem. 44:564573, doi: 10.1016/j.plaphy.2006.09.015.

Calvo, J.R., C. Gonzalez-Yanes, and M.D. Maldonado. 2013. The role of melatonin in the cells of the innate immunity: A review. J. Pineal Res. 55:103-120, doi: 10.1111/jpi.12075.

Campos, P.S., V. Quartin, J.C. Ramalho, and M.A. Nunes. 2003. Electrolyte leakage and lipid degradation account for cold sensitivity in leaves of Coffea sp. plants. J. Plant Physiol. 160:283-292, doi: 10.1078/0176-1617-00833.

Carr, M.K.V. 2001. The water relations and irrigation requirements of coffee. Exp. Agr. 37:1-36, doi: 10.1017/S0014479701001090.

Chen, K., L. Chen, J. Fan, and J. Fu. 2013. Alleviation of heat damage to photosystem II by nitric oxide in tall fescue. Photosynth. Res. 116:21-31, doi: 10.1007/s11120-013-9883-5.

Chen, Q., W.B. Qi, R.J. Reiter, W. Wei, and B.M. Wang. 2009. Exogenously applied melatonin stimulates root growth and raises endogenous indoleacetic acid in roots of etiolated seedlings of 
Brassica juncea. J. Plant Physiol. 166:324-328, doi: 10.1016/ j.jplph.2008.06.002.

DaMatta, F.M. 2004. Exploring drought tolerance in coffee: A physiological approach with some insights for plant breeding. Braz. J. Plant Physiol. 16:1-6, doi: 10.1590/s1677-04202004000100001.

DaMatta, F.M. and J.D.C. Ramalho. 2006. Impacts of drought and temperature stress on coffee physiology and production: A review. Braz. J. Plant Physiol. 18:55-81, doi: 10.1590/s167704202006000100006.

Ding, F., G. Wang, M. Wang, and S. Zhang. 2018. Exogenous melatonin improves tolerance to water deficit by promoting cuticle formation in tomato plants. Molecules 23, doi: 10.3390/molecules 23071605 .

Fahl, J.I., M.L.C. Carelli, J. Vega, and A.C. Magalhães. 1994. Nitrogen and irradiance levels affecting net photosynthesis and growth of young coffee plants (Coffea arabica L.). Intl. J. Hort. Sci. 69:161169, doi: 10.1080/14620316.1994.11515262.

Fan, J., Z. Hu, Y. Xie, Z. Chan, K. Chen, E. Amombo, L. Chen, and J. Fu. 2015. Alleviation of cold damage to photosystem II and metabolisms by melatonin in bermudagrass. Front. Plant Sci. 6:925, doi: 10.3389/fpls.2015.00925.

Fanjul, L., R. Arreola-Rodriguez, and M.P. Mendez-Castrejon. 2008. Stomatal responses to environmental variables in shade and sun grown coffee plants in Mexico. Exp. Agr. 21:249-258, doi: 10.1017/ S0014479700012606.

Farooq, M., A. Wahid, N. Kobayashi, D. Fujita, and S.M.A. Basra. 2009. Plant drought stress: Effects, mechanisms and management. Agron. Sustain. Dev. 29:185-212, doi: 10.1051/agro:2008021.

Foyer, C.H. and J.M. Fletcher. 2001. Plant antioxidants: Colour me healthy. Biologist (London) 48:115-120.

Fujita, Y., M. Fujita, R. Satoh, K. Maruyama, M.M. Parvez, M. Seki, K. Hiratsu, M. Ohme-Takagi, K. Shinozaki, and K. YamaguchiShinozaki. 2005. AREB1 is a transcription activator of novel ABREdependent ABA signalling that enhances drought stress tolerance in Arabidopsis. Plant Cell 17:3470-3488, doi: 10.1105/tpc.105.035659.

Hattori, A., H. Migitaka, M. Iigo, M. Itoh, K. Yamamoto, R. OhtaniKaneko, M. Hara, T. Suzuki, and R.J. Reiter. 1995. Identification of melatonin in plants and its effects on plasma melatonin levels and binding to melatonin receptors in vertebrates. Biochem. Mol. Biol. Intl. 35:627-634.

Heath, R.L. and L. Packer. 1968. Photoperoxidation in isolated chloroplasts. Arch. Biochem. Biophys. 125:189-198, doi: 10.1016/ 0003-9861(68)90654-1.

Hoagland, D.R. and D.I. Arnon. 1950. The water-culture method for growing plants without soil. California Agr. Expt. Sta. Circ. 347.

Hu, L., A. Bi, Z. Hu, E. Amombo, H. Li, and J. Fu. 2018. Antioxidant metabolism, photosystem II, and fatty acid composition of two tall fescue genotypes with different heat tolerance under high temperature stress. Front. Plant Sci. 9:1242, doi: 10.3389/fpls.2018.01242.

Huang, B., Y.E. Chen, Y.Q. Zhao, C.B. Ding, J.Q. Liao, C. Hu, L.J. Zhou, Z.W. Zhang, S. Yuan, and M. Yuan. 2019. Exogenous melatonin alleviates oxidative damages and protects photosystem II in maize seedlings under drought stress. Front. Plant Sci. 10:677, doi: 10.3389/fpls.2019.00677.

Jaleel, C.A., P. Manivannan, A. Wahid, M. Farooq, H.J. Al-Juburi, R. Somasundaram, and R. Panneerselvam. 2009. Drought stress in plants: A review on morphological characteristics and pigments composition. Intl. J. Agr. Biol. 11:100-105.

Jiang, C., Q. Cui, K. Feng, D. Xu, C. Li, and Q. Zheng. 2016. Melatonin improves antioxidant capacity and ion homeostasis and enhances salt tolerance in maize seedlings. Acta Physiol. Plant. 38:82, doi: 10.1007/s11738-016-2101-2.

Kabiri, R., A. Hatami, H. Oloumi, M. Naghizadeh, F. Nasibi, and Z. Tahmasebi. 2018. Foliar application of melatonin induces tolerance to drought stress in Moldavian balm plants (Dracocephalum moldavica) through regulating the antioxidant system. Folia Hort. 30:155-167, doi: 10.2478/fhort-2018-0016.
Kang, J.Y., H.I. Choi, M.Y. Im, and S.Y. Kim. 2002. Arabidopsis basic leucine zipper proteins that mediate stress-responsive abscisic acid signaling. Plant Cell 14:343-357, doi: 10.1105/tpc.010362.

Kang, K., K. Lee, S. Park, Y.S. Kim, and K. Back. 2010. Enhanced production of melatonin by ectopic overexpression of human serotonin $\mathrm{N}$-acetyltransferase plays a role in cold resistance in transgenic rice seedlings. J. Pineal Res. 49:176-182, doi: 10.1111/j.1600079X.2010.00783.x.

Korkmaz, A., E.J. Sanchez-Barcelo, D.X. Tan, and R.J. Reiter. 2009. Role of melatonin in the epigenetic regulation of breast cancer. Breast Cancer Res. Treat. 115:13-27, doi: 10.1007/s10549-0080103-5.

Lei, X.Y., R.Y. Zhu, G.Y. Zhang, and Y.R. Dai. 2004. Attenuation of cold-induced apoptosis by exogenous melatonin in carrot suspension cells: The possible involvement of polyamines. J. Pineal Res. 36:126-131, doi: 10.1046/j.1600-079x.2003.00106.x.

Li, B., T. Sang, L.Z. He, J. Sun, J. Li, and S.R. Guo. 2013. Exogenous spermidine inhibits ethylene production in leaves of cucumber seedlings under $\mathrm{NaCl}$ stress. J. Amer. Soc. Hort. Sci. 138:108-113, doi: 10.21273/Jashs.138.2.108.

Li, C., P. Wang, Z. Wei, D. Liang, C. Liu, L. Yin, D. Jia, M. Fu, and F. Ma. 2012. The mitigation effects of exogenous melatonin on salinityinduced stress in Malus hupehensis. J. Pineal Res. 53:298-306, doi: 10.1111/j.1600-079X.2012.00999.X.

Li, Y., H.X. Zhao, B.L. Duan, H. Korpelainen, and C.Y. Li. 2011. Effect of drought and ABA on growth, photosynthesis and antioxidant system of Cotinus coggygria seedlings under two different light conditions. Environ. Exp. Bot. 71:107-113, doi: 10.1016/j.envexpbot.2010.11.005.

Li, Y., N. He, J. Hou, L. Xu, C. Liu, J. Zhang, Q. Wang, X. Zhang, and X. Wu. 2018. Factors influencing leaf chlorophyll content in natural forests at the biome scale. Front. Ecol. Evol., doi: 10.3389/ fevo.2018.00064.

Liang, B., C. Ma, Z. Zhang, Z. Wei, T. Gao, Q. Zhao, F. Ma, and C. Li. 2018. Long-term exogenous application of melatonin improves nutrient uptake fluxes in apple plants under moderate drought stress. Environ. Exp. Bot. 155:650-661, doi: 10.1016/j.envexpbot.2018.08.016.

Liang, G., J. Liu, J. Zhang, and J. Guo. 2020. Effects of drought stress on photosynthetic and physiological parameters of tomato. J. Amer. Soc. Hort. Sci. 145:12-17, doi: 10.21273/jashs04725-19.

Liang, Y., D. Urano, K.L. Liao, T.L. Hedrick, Y. Gao, and A.M. Jones. 2017. A nondestructive method to estimate the chlorophyll content of Arabidopsis seedlings. Plant Methods 13:26, doi: 10.1186/s13007017-0174-6.

Lichtenthaler, H.K. 1987. Chlorophylls and carotenoids-Pigments of photosynthetic biomembranes. Methods Enzymol. 148:350-382, doi: 10.1016/0076-6879(87)48036-1.

Lima, A.L.S., F.M. DaMatta, H.A. Pinheiro, M.R. Totola, and M.E. Loureiro. 2002. Photochemical responses and oxidative stress in two clones of Coffea canephora under water deficit conditions. Environ. Exp. Bot. 47:239-247, doi: 10.1016/s0098-8472(01)00130-7.

Liu, A., Z. Hu, A. Bi, J. Fan, M.M. Gitau, E. Amombo, L. Chen, and J. Fu. 2016. Photosynthesis, antioxidant system and gene expression of bermudagrass in response to low temperature and salt stress. Ecotoxicology 25:1445-1457, doi: 10.1007/s10646-016-1696-9.

Livak, K.J. and T.D. Schmittgen. 2001. Analysis of relative gene expression data using real-time quantitative PCR and the $2^{-\Delta \Delta C}$ Method. Methods 25:402-408, doi: 10.1006/meth.2001.1262.

Lu, G., C. Gao, X. Zheng, and B. Han. 2009. Identification of OsbZIP72 as a positive regulator of ABA response and drought tolerance in rice. Planta 229:605-615, doi: 10.1007/s00425-0080857-3.

Ma, X., J. Zhang, P. Burgess, S. Rossi, and B. Huang. 2018. Interactive effects of melatonin and cytokinin on alleviating drought-induced leaf senescence in creeping bentgrass (Agrostis stolonifera). Environ. Exp. Bot. 145:1-11, doi: 10.1016/j.envexpbot.2017.10.010. 
Maxwell, K. and G.N. Johnson. 2000. Chlorophyll fluorescence-A practical guide. J. Expt. Bot. 51:659-668, doi: 10.1093/jxb/ 51.345 .659

Mittler, R. 2006. Abiotic stress, the field environment and stress combination. Trends Plant Sci. 11:15-19, doi: 10.1016/ j.tplants.2005.11.002.

Mofatto, L.S., A. Carneiro Fde, N.G. Vieira, K.E. Duarte, R.O. Vidal, J.C. Alekcevetch, M.G. Cotta, J.L. Verdeil, F. Lapeyre-Montes, M. Lartaud, T. Leroy, F. De Bellis, D. Pot, G.C. Rodrigues, M.F Carazzolle, G.A. Pereira, A.C. Andrade, and P. Marraccini. 2016. Identification of candidate genes for drought tolerance in coffee by high-throughput sequencing in the shoot apex of different apple cultivars. BMC Plant Biol. 16:94, doi: 10.1186/s12870-016-0777-5.

Murchie, E.H. and T. Lawson. 2013. Chlorophyll fluorescence analysis: A guide to good practice and understanding some new applications. J. Expt. Bot. 64:3983-3998, doi: 10.1093/jxb/ert208.

Nabi, R.B.S., R. Tayade, A. Hussain, K.P. Kulkarni, Q.M. Imran, B.-G. Mun, and B.-W. Yun. 2019. Nitric oxide regulates plant responses to drought, salinity, and heavy metal stress. Environ. Exp. Bot. 161:120-133, doi: 10.1016/j.envexpbot.2019.02.003.

Orellana, S., M. Yanez, A. Espinoza, I. Verdugo, E. Gonzalez, S. RuizLara, and J.A. Casaretto. 2010. The transcription factor SlAREB1 confers drought, salt stress tolerance and regulates biotic and abiotic stress-related genes in tomato. Plant Cell Environ. 33:2191-2208, doi: 10.1111/j.1365-3040.2010.02220.x.

Pinheiro, H.A., F.M. Damatta, A.R. Chaves, M.E. Loureiro, and C. Ducatti. 2005. Drought tolerance is associated with rooting depth and stomatal control of water use in clones of Coffea canephora. Ann. Bot. 96:101-108, doi: 10.1093/aob/mci154.

Posmyk, M.M., H. Kuran, K. Marciniak, and K.M. Janas. 2008. Presowing seed treatment with melatonin protects red cabbage seedlings against toxic copper ion concentrations. J. Pineal Res. 45:24-31, doi: 10.1111/j.1600-079X.2007.00552.x.

Reiter, R.J. 1997. Aging and oxygen toxicity: Relation to changes in melatonin. Age (Omaha) 20:201-213, doi: 10.1007/s11357-9970020-2.

Reiter, R.J., D.X. Tan, C. Osuna, and E. Gitto. 2000. Actions of melatonin in the reduction of oxidative stress. A review. J. Biomed. Sci. 7:444-458, doi: 10.1007/bf02253360.

Ribas, A.F., L.F.P. Pereira, and L.G.E. Vieira. 2006. Genetic transformation of coffee. Braz. J. Plant Physiol. 18:83-94, doi: 10.1590/ s1677-04202006000100007.

Rizhsky, L., H. Liang, and R. Mittler. 2002. The combined effect of drought stress and heat shock on gene expression in tobacco. J. Plant Physiol. 130:1143-1151, doi: 10.1104/pp.006858.

Shi, H., C. Jiang, T. Ye, D.X. Tan, R.J. Reiter, H. Zhang, R. Liu, and Z. Chan. 2015. Comparative physiological, metabolomic, and transcriptomic analyses reveal mechanisms of improved abiotic stress resistance in bermudagrass [Cynodon dactylon (L). Pers.] by exogenous melatonin. J. Expt. Bot. 66:681-694, doi: 10.1093/jxb/eru373. Strasser, R.J., A. Srivastava, and M. Tsimilli-Michael. 2000. The fluorescence transient as a tool to characterize and screen photosyn- thetic samples, p. 443-480. In: M. Yunus, U. Pathre, and P. Mohanty (eds.). Probing photosynthesis: Mechanism, regulation \& adaptation. Taylor and Francis, London, UK.

Talaat, N.B., B.T. Shawky, and A.S. Ibrahim. 2015. Alleviation of drought-induced oxidative stress in maize (Zea mays L.) plants by dual application of 24-epibrassinolide and spermine. Environ. Exp. Bot. 113:47-58, doi: 10.1016/j.envexpbot.2015.01.006.

Tan, D.X., R. Hardeland, L.C. Manchester, A. Korkmaz, S. Ma, S. Rosales-Corral, and R.J. Reiter. 2012. Functional roles of melatonin in plants, and perspectives in nutritional and agricultural science. J. Expt. Bot. 63:577-597, doi: 10.1093/jxb/err256.

Tan, D.X., L.C. Manchester, P. Helton, and R.J. Reiter. 2007. Phytoremediative capacity of plants enriched with melatonin. Plant Signal. Behav. 2:514-516, doi: 10.4161/psb.2.6.4639.

Tan, D.X., L.C. Manchester, R.J. Reiter, B.F. Plummer, J. Limson, S.T. Weintraub, and W. Qi. 2000. Melatonin directly scavenges hydrogen peroxide: A potentially new metabolic pathway of melatonin biotransformation. Free Radic. Biol. Med. 29:1177-1185, doi: 10.1016/s0891-5849(00)00435-4.

Wang, C., J. He, T.H. Zhao, Y. Cao, G. Wang, B. Sun, X. Yan, W. Guo, and M.H. Li. 2019. The smaller the leaf is, the faster the leaf water loses in a temperate forest. Front. Plant Sci. 10:58, doi: 10.3389/ fpls.2019.00058.

Wang, P., X. Sun, C. Li, Z. Wei, D. Liang, and F. Ma. 2013. Long-term exogenous application of melatonin delays drought-induced leaf senescence in apple. J. Pineal Res. 54:292-302, doi: 10.1111/ jpi.12017.

Wei, W., Q.T. Li, Y.N. Chu, R.J. Reiter, X.M. Yu, D.H. Zhu, W.K. Zhang, B. Ma, Q. Lin, J.S. Zhang, and S.Y. Chen. 2015. Melatonin enhances plant growth and abiotic stress tolerance in soybean plants. J. Expt. Bot. 66:695-707, doi: 10.1093/jxb/eru392.

Willekens, H., S. Chamnongpol, M. Davey, M. Schraudner, C. Langebartels, M. Van Montagu, D. Inze, and W. Van Camp. 1997. Catalase is a sink for $\mathrm{H}_{2} \mathrm{O}_{2}$ and is indispensable for stress defence in $\mathrm{C}_{3}$ plants. EMBO J. 16:4806-4816, doi: 10.1093/emboj/16.16.4806. Xia, H., Z. Ni, R. Hu, L. Lin, H. Deng, J. Wang, Y. Tang, G. Sun, X. Wang, H. Li, M. Liao, X. Lv, and D. Liang. 2020. Melatonin alleviates drought stress by a non-enzymatic and enzymatic antioxidative system in kiwifruit seedlings. Intl. J. Mol. Sci. 21: doi: 10.3390/ijms21030852.

Yusuf, M.A., D. Kumar, R. Rajwanshi, R.J. Strasser, M. TsimilliMichael, Govindjee, and N.B. Sarin. 2010. Overexpression of gamma-tocopherol methyl transferase gene in transgenic Brassica juncea plants alleviates abiotic stress: Physiological and chlorophyll a fluorescence measurements. Biochim. Biophys. Acta 1797:14281438, doi: 10.1016/j.bbabio.2010.02.002.

Zhang, N., B. Zhao, H.J. Zhang, S. Weeda, C. Yang, Z.C. Yang, S. Ren, and Y.D. Guo. 2013. Melatonin promotes water-stress tolerance, lateral root formation, and seed germination in cucumber (Cucumis sativus L.). J. Pineal Res. 54:15-23, doi: 10.1111/j.1600079X.2012.01015.x. 
Supplemental Table 1. Primer sequences used in the study of relative expression of photosynthetic genes under drought stress tolerance in Coffea arabica seedlings after exogenous melatonin application.

\begin{tabular}{|c|c|c|c|c|}
\hline \multirow{2}{*}{$\frac{\text { Gene }^{\mathrm{z}}}{P A O}$} & \multirow{2}{*}{$\begin{array}{l}\text { Accession no. } \\
\text { EC 1.14.15.17 }\end{array}$} & \multicolumn{2}{|c|}{ Primer sequences $\left(5^{\prime}-3^{\prime}\right)$} & \multirow{2}{*}{$\frac{\operatorname{Tm}\left({ }^{\circ} \mathrm{C}\right)^{\mathrm{y}}}{55.5}$} \\
\hline & & Forward & CCGGTCAATTGTTTGTAGTGCT & \\
\hline & & Reverse & TGACGTCCAATGCTCATGCC & 58.5 \\
\hline$R B C S 2$ & EC 4.1.1.39 & Forward & CCGCAGTGGATGGGTTCCTT & 60.8 \\
\hline \multirow[t]{2}{*}{$A R E B$} & At1g45249 & Forward & CAGCAGCAAGATCACGAGCC & 60.0 \\
\hline & & Reverse & GCCTCCACGCTGTTGGTTCA & 60.7 \\
\hline EF1a & GR996930.1 & Forward & GGTGGTTTTGAAGCTGGTATTTCT & 55.2 \\
\hline \multirow[t]{2}{*}{ RPL39 } & GT720707.1 & Forward & GCGAAGAAGCAGAGGCAGAA & 58.1 \\
\hline & & Reverse & TTGGCATTGTAGCGGATGGT & 57.1 \\
\hline
\end{tabular}

${ }^{\mathrm{z}} \mathrm{PAO}=$ chlorophyll degradation gene encoding pheophorbide $a$ oxygenase. $R B C S 2=$ photosynthetic gene encoding ribulose-1,5-bisphosphate oxygenase (Rubisco) protein. $A R E B=$ drought-related gene encoding abscisic acid-responsive element binding protein. $E F 1 a=$ reference gene. $R P L 39=$ reference gene.

${ }^{\mathrm{y}}$ Melting temperature $(\mathrm{Tm})\left({ }^{\circ} \mathrm{C}\right) 11$. 